\begin{tabular}{l} 
Bentham Open \\
\hline CrossMark \\
\hline DoI: $10.2174 / 1874364101610010017$
\end{tabular}

\title{
Retinopathy of Prematurity in Neonates and its Risk Factors: A Seven Year Study in Northern Iran
}

\author{
Seyed Ahmad Rasoulinejad ${ }^{1}$ and Mohammad Montazeri, ${ }^{2, *}$ \\ ${ }^{\prime}$ Department of Ophthalmology, Babol University of Medical Sciences, Babol, Iran \\ ${ }^{2}$ Young Researchers Club, Islamic Azad University, Babol branch, Babol, Iran
}

\begin{abstract}
:
Purpose:

An important cause of avoidable childhood blindness is retinopathy of prematurity (ROP) in countries with high human development index and also in some emerging economies countries. To date, no research have been conducted on analyzing data of ROP prevalence in Babol, and this is the first research performed on ROP in this area.
\end{abstract}

\section{Methods:}

All VLBW babies who referred to Babol ophthalmology center over the seven years, from February 2007 to December 2013 were enrolled in this descriptive cross-sectional research. A team of researchers recorded patients' information completely in check lists. A single experienced ophthalmologist performed ophthalmologic examination of patients.

\section{Result:}

The incidence of ROP of any stage in Babol was determined to be 306 (45\%) of all babies enrolled in this study. In present study, key risk factors of ROP were low gestational age, oxygen therapy more than five days and low birth weight.

\section{Conclusion:}

The findings of current study demonstrate that the main risk factors of developing ROP in newborns are multiple gestation, low birth weight, oxygen therapy for more than five day. Therefore, the progression of ROP to blindness will be prevented by a high index of suspicion, suitable screening, prompt diagnosis, and early treatment.

Keywords: Birth weight, multiple gestation, prevalence, retinopathy of Prematurity, risk factors, neonates.

\section{INTRODUCTION}

Retinopathy of prematurity (ROP) affects immature vasculature of premature infants' eyes. This disease can appear in mild and aggressive forms. No visual sequelae is resulted in the mild form, while aggressive type is along with neovascularization and develop to retinal detachment and blindness [1,2]. The prevalence of ROP has enhanced because of surviving smaller and younger infants [3].

In countries with high human development index and also in some emerging economies countries, this disease is a main avoidable cause of childhood blindness [4]. ROP is more prevalent in premature babies with low birth weight. Fielder reported the development of ROP in 51\% of infants weighing less than $1700 \mathrm{~g}$. Overall, the evidence of ROP is recognized for more than $50 \%$ of premature babies weighing less than 1250 gr at birth, and stage 3 ROP is observed in approximately $10 \%$ of these babies $[5,6]$.

\footnotetext{
* Address correspondence to this author at the Department of Young Researchers Club, Islamic Azad University, Babol Branch, Mazandaran, Iran. Tel: +98 11 32415102; Fax: +98 11 32415159; E-mail: mm.montazeri@gmail.com
} 
On average, 500-700 cases of blindness as a result of ROP are annually reported among American newborns. This can be stated as 30,000 life years of vision in terms of life years of blindness. 2100 newborns will annually be affected by cicatricial sequel such as myopia, blindness, strabismus, and late-onset retinal detachment [7 - 9]. The thumb rule is that several types of strabismus or refractive error will progress in about $20 \%$ of all premature newborns by 3 years of age [10]. For this reason, babies younger than 32 weeks or less than 1500 gr are given follow-up care every 6 months, regardless not or whether ROP is present $[5,11]$.

Low GA, low BW, sex, oxygen therapy, intra ventricular hemorrhage (IVH), phototherapy and blood transfusion are known as risk factors of this disease [12].

There has been no research until now to analyze data of ROP incidence in north of Iran. Accordingly, this is the first research conducted on ROP prevalence in Babol, which is one of the deprived and developing provinces in north Iran.

\section{MATERIALS AND METHODOLOGY}

All very low birth weight (VLBW) babies referred to Babol ophthalmology center over the seven years from February 2007 to December 2013 were entered in this descriptive cross-sectional research. The study obtained ethics approval from the Ethics Committee of Babol University of Medical Sciences. Easy sampling method is used to select the patients in this study. Babies who died before a retinal examination were omitted from the study.

Unlike most international guidelines, newborns with a gestational age less than 36 weeks and $2500 \mathrm{~g}$ birth weight (BW) were not omitted from the study as there is no screening criteria for ROP in Iran. All information corresponding to sex, gestational age (GA), birth weight, presence of respiratory distress syndrome (RDS), delivery type, oxygen therapy and sepsis were recorded by a team of scientists in a check list. A single experienced ophthalmologist performed ophthalmologic examination of patients.

T-test was applied to perform a comparison between two groups in the terms of the GA, BW, infant's age at examination and oxygen therapy. The comparison of categorical and qualitative variables including sepsis, oxygen therapy, etc. in groups was performed using chi-square test. In order to identify the probability of ROP in study groups, odds ratio (OR) was obtained by using logistic regression statistic tests. SPSS software (Version 21) was used to analysis all data. A $\mathrm{P}$ value $<0.05$ was considered statistically significant.

\section{RESULT}

During the study, 680 of 865 VLBW newborns who were referred were followed up for ROP development. 425 (62.5\%) males and 255 (37.5\%) females were involved in ROP group. Table 1 shows the average birth weight was $1713.9 \pm 416.7$ grams and the average gestational age was $31.45 \pm 2.21$ weeks (7\% was 25-28 week, 55\% was 29-32 week and $38 \%$ was more than 32 week).

The overall incidence of ROP in any stage was 306 (45\%) among babies who referred to Babol ophthalmology center. Of 306 subjects, 52 (16.99\%) subjects were in stage I of ROP, $193(63.07 \%)$ subjects were in stage II and 61 $(19.93 \%)$ subjects were in stage III or III $^{+}$.

Table 1. Demographic and perinatal characteristics of the study neonates.

\begin{tabular}{|c|c|}
\hline Characteristic & No (N \%) \\
\hline Sex & $425(62.5 \%)$ \\
Male & $255(37.5 \%)$ \\
Female & $1713.9 \pm 416.7$ \\
\hline Mean birth weight (gr) & $48(7 \%)$ \\
\hline Birth weight(groups) & $197(29 \%)$ \\
$500-1000$ & $292(43 \%)$ \\
$1001-1500$ & $143(21 \%)$ \\
$1501-2000$ & $48(7 \%)$ \\
$>2000$ & $374(55 \%)$ \\
Gestational age & $258(38 \%)$ \\
$25-28$ & $201(29.5 \%)$ \\
$29-32$ & $479(70.5 \%)$ \\
\hline Delivery type & \\
NVD & \\
CS & \\
\hline
\end{tabular}


(Table ए) contd.....

\begin{tabular}{|c|c|}
\hline Characteristic & No (N \%) \\
\hline RDS & $524(77 \%)$ \\
$156(23 \%)$ \\
Yes & $113(16.7 \%)$ \\
\hline No & $567(83.3 \%)$ \\
\hline Sepsis & Yes \\
No & $5.21 \pm 2.45$ \\
\hline
\end{tabular}

Table 2 shows the results of logistic regression for all independent variables. There was a significant relationship between GA of 32 weeks or less and ROP $(\mathrm{P}<0.001)$.

Furthermore, it was observed that babies with BW of less than $1500 \mathrm{~g}$ are 3.5 times more at risk for ROP compared to babies with $1500 \mathrm{~g}$ or more. A significant relationship was observe between sepsis and $\mathrm{ROP}(\mathrm{P}<0.001)$.

Table 2. Simple regression analysis results for ROP.

\begin{tabular}{|c|c|c|c|c|c|c|}
\hline \multicolumn{2}{|c|}{ Characteristic } & $\begin{array}{l}\text { ROP } \\
\text { N(\%) }\end{array}$ & $\begin{array}{c}\text { No ROP } \\
\text { N(\%) }\end{array}$ & OR & $\mathrm{Cl}$ & P-Value \\
\hline \multirow{2}{*}{ Sex } & Male & $211(69 \%)$ & $214(57.2 \%)$ & \multirow{2}{*}{0.787} & \multirow{2}{*}{$0.034-1.78$} & \multirow{2}{*}{0.50} \\
\hline & Female & $95(31 \%)$ & $160(42.8 \%)$ & & & \\
\hline \multirow{2}{*}{ GA } & $<32 \mathrm{~W}$ & $141(46 \%)$ & $71(19 \%)$ & \multirow{2}{*}{2.913} & \multirow{2}{*}{$1.237-6.862$} & \multirow{2}{*}{0.01} \\
\hline & $\geq 32 \mathrm{w}$ & $165(54 \%)$ & $303(81 \%)$ & & & \\
\hline \multirow{2}{*}{$\begin{array}{l}\text { Oxygen therapy } \\
>5 \text { day }\end{array}$} & Yes & $267(87.2 \%)$ & $245(65.5 \%)$ & \multirow{2}{*}{1.793} & \multirow{2}{*}{$0.629-5.110$} & \multirow{2}{*}{$0 / 32$} \\
\hline & No & $39(12.8 \%)$ & $129(34.5 \%)$ & & & \\
\hline \multirow{2}{*}{ RDS } & Yes & $141(46 \%)$ & $183(49 \%)$ & \multirow{2}{*}{0.853} & \multirow{2}{*}{$0.380-1.913$} & \multirow{2}{*}{$0 / 87$} \\
\hline & No & $165(54 \%)$ & $191(51 \%)$ & & & \\
\hline \multirow{2}{*}{ Sepsis } & Yes & $65(21 \%)$ & $41(10 \%)$ & \multirow{2}{*}{2.889} & \multirow{2}{*}{$1.093-7.633$} & \multirow{2}{*}{0.04} \\
\hline & No & $241(79 \%)$ & $333(90 \%)$ & & & \\
\hline \multirow{2}{*}{ Birth weight(gram) } & $<1500 \mathrm{gr}$ & $133(43.5 \%)$ & $83(22.1 \%)$ & \multirow{2}{*}{3.512} & \multirow{2}{*}{$1.415-8.719$} & \multirow{2}{*}{0.007} \\
\hline & $1500 \mathrm{gr} \leq$ & $173(56.5 \%)$ & $291(77.9 \%)$ & & & \\
\hline ROP stage & $\begin{array}{c}\text { I } \\
\text { II } \\
\text { III }\end{array}$ & $\begin{array}{c}52(16.99 \%) \\
193(63.07 \%) \\
61(19.93 \%)\end{array}$ & $\begin{array}{l}0(0 \%) \\
0(0 \%) \\
0(0 \%)\end{array}$ & 2.713 & $1.123-7.766$ & 0.001 \\
\hline
\end{tabular}

In ROP group, the mean oxygen therapy was $7.12 \pm 4.32$ day and this value in healthy group was $3.23 \pm 2.18$ day. Thus, there is no significant relationship between oxygen therapy with ROP $(\mathrm{P}>0.05)$.

\section{DISCUSSION}

In current study, the incidence of ROP in any stage, from February 2007 to December 2013 was 306 (45\%) among babies referred to Babol ophthalmology center. ROP is considered as an important avoidable cause of blindness in children in countries with high human development index and also in some emerging economies countries [4]. One country is different from another one in terms of the ROP prevalence depending on birth weights, gestational age, and risk factors. Three epidemics have been reported since 1942 after recognizing ROP: The first epidemic was during 1940-1945 when oxygen therapy was recognized as the main reason; the next one occurred between 1960-1970 due to developing neonatal care in industrial countries that enhanced survival of babies with ELBW; and the last one from 1980 until now because of increasing the survival of preterm babies with gestational age more than 32 weeks and a birth weight greater than 1500 grams using the newborn care accessible in developing countries with limited resources [13, 14].

The ROP rate in the current study was $45 \%$, which was higher as compared to available literature in this context including 32.4 \% in Pakistan [15], $29.5 \%$ in Tehran [16], $29.2 \%$ in Singapore [18], $29 \%$ in Kerman (southern Iran) [19], and $10.45 \%$ in the United States [17]. Moreover, Sabzehi et al. [20] reported that the ROP incidence in Tehran was $17.4 \%$ in 3 years study. In another study conducted by Mousavi et al. [21], the prevalence of ROP in Farabi hospital of Tehran was 34.4\% in 4 years. Furthermore, the ROP prevalence was reported 37.1\% by Mutlu et al. [22].

The outstanding risk factors for ROP have been addressed in this study; our findings are in a good accordance with those obtained from other studies. it was found that multiple gestations is an independent risk factor in progression of 
ROP in studied subjects as well as the results of Blumenfield's study, although there was no difference between the ROP severity for children of a multiple gestation and infants of singletons [23]. In a research conducted by RiaziEsfahani et al. [24], there was observed no significant difference in the rate or severity of ROP between babies of a multiple gestation and singletons unlike the study of Dos Santos Motta et al. [25] on 26 cases in which multiple gestation was considered as a risk factor for progression and severity of ROP.

It was found that oxygen therapy duration is an independent risk factor for ROP that was $>40$ days, $>30$ days, $>$ seven days and $>$ five days in the studied of Niwald et al. [26], Pinheiro et al. [27], Hakeem et al. [28] and present study, respectively.

\section{CONCLUSION}

The findings of current study demonstrate that the main risk factors for infants to develop ROP are multiple gestation, low birth weight, oxygen therapy for more than five days. Therefore, the progressing ROP to blindness will be prevented with a high index of suspicion, apposite screening, rapid diagnosis, and early treatment.

\section{CONFLICT OF INTEREST}

The authors confirm that this article content has no conflict of interest.

\section{ACKNOWLEDGEMENTS}

Declared none.

\section{REFERENCES}

[1] American Academy of Pediatrics (Section on Ophthalmology). Screening examination of premature infants for retinopathy of prematurity. Pediatrics 2001; 108(3): 809-11.

[http://dx.doi.org/10.1542/peds.108.3.809] [PMID: 11533356]

[2] American Academy of Pediatrics (Section on Ophthalmology); American Academy of Ophthalmology; American Association for Pediatric Ophthalmology and Strabismus. Screening examination of premature infants for retinopathy of prematurity. Pediatrics 2006; 117(2): 572-6. [http://dx.doi.org/10.1542/peds.2005-2749] [PMID: 16452383]

[3] Phelps D. Retinopathy of prematurity. In: Fanaroff A, Martin R, Eds. Neonatal-Perinatal medicine. Philadelphia, PA: Saunders Elsevier 2011; pp. 1764-70.

[4] Filho FJB, Eckert GU, Procianoy L, Barros CK, Procianoy RS. Incidence and risk factors for retinopathy of prematurity in very low and in extremely low birth weight infants in a unit-based approach in southern Brazil. Eye (Lond) 2009; 23(1): 25-30. [http://dx.doi.org/10.1038/sj.eye.6702924] [PMID: 17618242]

[5] Chen Y, Li XX, Yin H, et al. Risk factors for retinopathy of prematurity in six neonatal intensive care units in Beijing, China. Br J Ophthalmol 2008; 92(3): 326-30.

[http://dx.doi.org/10.1136/bjo.2007.131813] [PMID: 18303154]

[6] Binkhathlan AA, Almahmoud LA, Saleh MJ, Srungeri S. Retinopathy of prematurity in Saudi Arabia: incidence, risk factors, and the applicability of current screening criteria. Br J Ophthalmol 2008; 92(2): 167-9. [http://dx.doi.org/10.1136/bjo.2007.126508] [PMID: 18227198]

[7] Gilbert C. Retinopathy of prematurity: a global perspective of the epidemics, population of babies at risk and implications for control. Early Hum Dev 2008; 84(2): 77-82. [http://dx.doi.org/10.1016/j.earlhumdev.2007.11.009] [PMID: 18234457]

[8] Gergely K, Gerinec A. Retinopathy of prematurity--epidemics, incidence, prevalence, blindness. Bratisl Lek Listy (Tlacene Vyd) 2010; 111(9): 514-7.

[PMID: 21180268]

[9] Ahmadpour-Kacho M, Motlagh AJ, Rasoulinejad SA, Jahangir T, Bijani A, Pasha YZ. Correlation between hyperglycemia and retinopathy of prematurity. Pediatr Int 2014; 56(5): 726-30. [http://dx.doi.org/10.1111/ped.12371] [PMID: 24803073]

[10] Good WV, Hardy RJ, Dobson V, et al. The incidence and course of retinopathy of prematurity: findings from the early treatment for retinopathy of prematurity study. Pediatrics 2005; 116(1): 15-23. [http://dx.doi.org/10.1542/peds.2004-1413] [PMID: 15995025]

[11] Fielder AR, Reynolds JD. Retinopathy of prematurity: clinical aspects. Semin Neonatol 2001; 6(6): 461-75. [http://dx.doi.org/10.1053/siny.2001.0091] [PMID: 12014887]

[12] Gandhi B, Rich W, Finer N. Time to achieve stable pulse oximetry values in VLBW infants in the delivery room. Resuscitation 2013; 84(7): 970-3.

[http://dx.doi.org/10.1016/j.resuscitation.2012.12.007] [PMID: 23238422] 
[13] Bell MJ, Ternberg JL, Feigin RD, et al. Neonatal necrotizing enterocolitis. Therapeutic decisions based upon clinical staging. Ann Surg 1978; 187(1): 1-7. [http://dx.doi.org/10.1097/00000658-197801000-00001] [PMID: 413500]

[14] Clemett R, Darlow B. Results of screening low-birth-weight infants for retinopathy of prematurity. Curr Opin Ophthalmol 1999; 10(3): $155-63$. [http://dx.doi.org/10.1097/00055735-199906000-00001] [PMID: 10537772]

[15] Taqui AM, Syed R, Chaudhry TA, Ahmad K, Salat MS. Retinopathy of prematurity: frequency and risk factors in a tertiary care hospital in Karachi, Pakistan. J Pak Med Assoc 2008; 58(4): 186-90. [PMID: 18655427]

[16] Karkhaneh R, Mousavi SZ, Riazi-Esfahani M, et al. Incidence and risk factors of retinopathy of prematurity in a tertiary eye hospital in Tehran. Br J Ophthalmol 2008; 92(11): 1446-9. [http://dx.doi.org/10.1136/bjo.2008.145136] [PMID: 18728050]

[17] Lad EM, Nguyen TC, Morton JM, Moshfeghi DM. Retinopathy of prematurity in the United States. Br J Ophthalmol 2008; $92(3): 320-5$. [http://dx.doi.org/10.1136/bjo.2007.126201] [PMID: 18303153]

[18] Shah VA, Yeo CL, Ling YL, Ho LY. Incidence, risk factors of retinopathy of prematurity among very low birth weight infants in Singapore. Ann Acad Med Singapore 2005; 34(2): 169-78. [PMID: 15827664]

[19] Ghaseminejad A, Niknafs P. Distribution of retinopathy of prematurity and its risk factors. Iran J Pediatr 2011; 21(2): 209-14. [PMID: 23056789]

[20] Sabzehei MK, Afjeh SA, Farahani DA, Shamshiri AR, Esmaili F. Retinopathy of prematurity: incidence, risk factors, and outcome. Arch Iran Med 2013; 16(9): 507-12. [PMID: 23981152]

[21] Mousavi SZ, Esfahani RM, Roohipoor R, et al. Characteristics of advanced stages of retinopathy of prematurity. Indian J Ophthalmol 2010; 22(2): $19-24$.

[22] Mutlu FM, Altinsoy HI, Mumcuoglu T, et al. Screening for retinopathy of prematurity in a tertiary care newborn unit in Turkey: frequency, outcomes, and risk factor analysis. J Pediatr Ophthalmol Strabismus 2008; 45(5): 291-8.

[http://dx.doi.org/10.3928/01913913-20080901-12] [PMID: 18825902]

[23] Blumenfeld LC, Siatkowski RM, Johnson RA, Feuer WJ, Flynn JT. Retinopathy of prematurity in multiple-gestation pregnancies. Am J Ophthalmol 1998; 125(2): 197-203. [http://dx.doi.org/10.1016/S0002-9394(99)80092-0] [PMID: 9467447]

[24] Riazi-Esfahani M, Alizadeh Y, Karkhaneh R, et al. Retinopathy of prematurity: single versus multiple-birth pregnancies. J Ophthalmic Vis Res 2008; 3(1): 47-51. [PMID: 23479522]

[25] Dos Motta SMM, Filho FJB, Coblentz J, Fiorot CA. Multiple pregnancies and its relationship with the development of retinopathy of prematurity (ROP). Clin Ophthalmol 2011; 5: 1783-7. [PMID: 22267912]

[26] Niwald A. Risk factors of $3^{\text {rd }}$ stage retinopathy of prematurity progression. Klin Oczna 2000; 102(6): 449-53. [PMID: 11392808]

[27] Pinheiro AM, Silva WA, Bessa CG, Cunha HM, Ferreira MA, Gomes AH. Incidence and risk factors of retinopathy of prematurity in University Hospital Onofre Lopes, Natal (RN)-Brazil. Arq Bras Oftalmol 2009; 72(4): 451-6. [http://dx.doi.org/10.1590/S0004-27492009000400005] [PMID: 19820782]

[28] Hakeem AH, Mohamed GB, Othman MF. Retinopathy of prematurity: a study of prevalence and risk factors. Middle East Afr J Ophthalmol 2012; 19(3): 289-94. [http://dx.doi.org/10.4103/0974-9233.97927] [PMID: 22837621]

Received: March 29, $2015 \quad$ Revised: June 17, 2015 Accepted: June 17,2015

(C) Rasoulinejad and Montazeri; Licensee Bentham Open

This is an open access article licensed under the terms of the Creative Commons Attribution-Non-Commercial 4.0 International Public License (CC BY-NC 4.0) (https://creativecommons.org/licenses/by-nc/4.0/legalcode), which permits unrestricted, non-commercial use, distribution and reproduction in any medium, provided the work is properly cited. 